\title{
International Migration Decision-Making and Destination Selection Among Skilled Migrants
}

\author{
Aidan S. Tabor, Taciano L. Milfont, and Colleen Ward \\ Centre for Applied Cross-Cultural Research, School of Psychology, Victoria University of Wellington, Wellington, New Zealand
}

\begin{abstract}
T his research explored how skilled, self-selected migrants make a decision to leave their country of origin and choose a destination. Data were gathered through semi-structured interviews with 20 pre-departure and 26 post-arrival migrants to New Zealand from the United Kingdom/Ireland, India and South Africa. A thematic analysis was conducted separately for each country's data. For these migrants, the decision process contained three major decisions: whether, where and when to go. Regarding the question of whether to go, key factors were both intrapersonal and social. New Zealand was selected as a destination of choice due to quality of life, safety, environment, cultural similarity, job opportunities and the perception that migrants were wanted. On the question of when to go, the decision process was a negotiation between partners, and often extended family, which occurred over a long period of time.
\end{abstract}

Keywords: global careers, mobility, expatriation, self-initiated expatriation

Since about $3.2 \%$ of the world's population lives outside of their country of birth, amounting to about 232 million people, the phenomenon of international migration is clearly an important aspect of modern life (United Nations, 2013). The majority of research into international migration decision-making has studied people coming from less developed countries to more developed countries; for example, Philippines-U.S. migration, Nuie-New Zealand migration, and West AfricanNetherlands migration (Connell, 2008; De Jong, Root, Gardner, Fawcett, \& Abad, 1986; Hamer, 2008). Studies of people leaving first world countries are much more rare (Benson \& O’Reilly, 2009; Dashefsky, DeAmicis, Laserwitz, \& Tabory, 1992; Stone \& Stubbs, 2007; Tabor \& Milfont, 2011; van Dalen \& Henkens, 2007). To understand how the process of migration decision-making works, researchers need to consider a wide range of migration streams. But what do we know of this complex and important decision that so many people are making?

Previous studies have indicated that the process of migration begins well before departure (JasinskajaLahti \& Yijälä, 2011; Tabor \& Milfont, 2011; Tartakovsky, 2012; Yijälä \& Jasinskaja-Lahti, 2010). Researchers have repeatedly linked intrapersonal factors to migration decisions (Frieze \& Li, 2010), meaning that the decision essentially starts within the personality of the decisionmaker. People who are more assertive, patient, work- focused and less family centred are more likely to want to move (Boneva \& Frieze, 2001; Boneva et al., 1998; Boneva, Frieze, Ferligoj, Pauknerova, \& Orgocka, 1997; Frieze et al., 2004; Frieze, Hansen, \& Boneva, 2006; Gibson \& McKenzie, 2011). Yet migration desires are both influenced by and influence the social context within which the person exists.

\section{Social Context in Migration}

In their study of Asian migrants to New Zealand, Ho and Bedford (2008) emphasised the importance of viewing migration as a multigenerational, multinational process, as family members often entered and left New Zealand to find work. This is supported by research on migration networks (also termed chain migration), which views social networks in the destination as facilitators for the move (Choldin, 1973; Fawcett, 1989; Massey, Alarcon, Durand, \& Gonsalez, 1987). Clearly, there is a social fabric within which the migration decision-making process occurs. To understand decision-making in a social context requires looking beyond the psychological research that focusses on the individual and into the research on the family as a unit (Chant \& Radcliffe, 1992).

Demographers and economists have long considered households as the base unit of migration studies (Graves \& Linneman, 1979; Konseiga, 2007; Mincer, 1978; Stark \& Taylor, 1989), but relatively little work has been done on how these households negotiate the international 
migration decision, with studies of internal migration being more common (de Haas \& Fokkema, 2010; King \& Skeldon, 2010; Le, Tissington, \& Budhwar, 2010; Rabe, 2011; Tsegai, 2007). The problem is that household theories of migration consider a household to be composed of actors with equal power and agreed aims, though this is quite often not the case, especially in cultures where women have less power than men in the family decisionmaking (de Haas \& Fokkema, 2010; Gubhaju \& De Jong, 2009; Hoang, 2011; Stecklov, Carletto, Azzarri, \& Davis, 2010).

In addition, research has also shown that partners can have differing goals in the migration process (Gubhaju \& De Jong, 2009; Pedraza, 1991) and that consensus building is often done through discussion (Adams, 2004; De Jong, Warland, \& Root, 1998). Not only are couples involved in the decision, but also others, such as extended family, children and friends, can have influence in the decision-making process (Adams, 2004). How family is defined is a key aspect of this type of research. Though individualists tend to see family as primarily being the nuclear family (parents and their minor children), collectivists are more inclusive of grandparents, adult siblings, cousins, aunts and uncles in their thinking (Georgas et al., 2001). As described in Adams' (2004) research, the role of these extended family members in the migration decision is also important. Similarly, Mulder (2007) argued that family context is critical to migration decisions even in individualist countries. British pre-departure migrants to New Zealand reported a drop in levels of social support from extended family when they informed the family of the planned move (Tabor \& Milfont, 2012). But nowhere is the extended family likely to be as influential as in collectivist cultures, as evidenced by the continuing strong relationships, both financial and social, of migrants from countries such as Vietnam (Thai, 2012). This is also demonstrated in Indian rural-urban internal migration, which has been characterised as family decision-making, wherein the head of the household (the eldest male) makes the decision about which family members are to migrate (Bhattacharyya, 1985).

Massey's work on the pattern of Mexico-U.S. immigration sheds light on the importance of other social networks that extend beyond family boundaries, including friendship and community ties (Massey, 1999; Massey et al., 1987). Scholars have recognised that having connections in a destination facilitates the transition between country of origin and destination, particularly in areas such as employment and housing (Boyd, 1989; Castles \& Miller, 2003; MacDonald \& MacDonald, 1964). These social networks are composed of both kin and friendship connections and tend to become self-sustaining over time (de Haas, 2010). Similarly, a panel study of migration into the European Union found that cultural and historic ties, as well as social networks, were strongly linked to destination (Pedersen, Pytlikova, \& Smith, 2008).
Overall, decision-making about migration appears to be influenced by these kinds of social networks, as contacts abroad can provide support to the pre-departure migrant (Adelman, 1988; Gubhaju \& De Jong, 2009; Haug, 2008; Ryan, 2008; van Dalen \& Henkens, 2007). In a study of North Americans moving to Israel, personal contacts in the destination were a major source of informational social support during the decision-making process (Amit \& Riss, 2007). Even interactions with others via online forums can be a major source of informational support and encouragement for the move (Tabor \& Milfont, 2013). What is unclear is the extent to which migration networks influence the choice of destination for a potential migrant, particularly those who are highly skilled and have the option of multiple destinations.

\section{Reasons for International Moves}

Economic theories suggest the reasons are purely financial (Boyle, 2009), but research from New Zealand has already found ample evidence for non-financial aspects, such as environment, as motivation for migrants (Department of Labour, 2009). The key reasons that migrants choose to leave their country of origin are recognised as being economic, political, cultural, family, and career factors (Carr, Inkson, \& Thorn, 2005). Many studies of migration decision-making have focused on these reasons for the move, usually categorising them as push/pull or macro/micro factors (Anas \& Wickremasinghe, 2010; Bushin, 2009; De Jong \& Gardner, 1981; Haug, 2008; Kontuly, Smith, \& Heaton, 1995; Schoorl et al., 2000). Push and pull factors respectively focus on evaluations of certain characteristics in the source and destination countries (e.g., crime). As an example of the importance of pull factors, results of a longitudinal survey showed that the main reasons reported for selecting New Zealand as a destination were: relaxed pace of life/lifestyle (44\%), climate or clean green environment (40\%), and a better future for children (39\%; Department of Labour, 2009). But there was also some variability in reasons reported by migration stream. For example, migrants from the United Kingdom/Ireland were most likely to give 'relaxed pace of life' and 'climate/clean green environment' as their reasons.

As mentioned above, social context, and in particular, contacts at the destination can also function as pull factors. In the year to February 2015, more than 47,000 people arrived in New Zealand on residency or work visas (Statistics New Zealand, 2015). What were the reasons that drew them here? Findings from the New Zealand government's Immigration Survey Monitoring Programme, which tracked responses from 8,000 migrants from the skilled, family and work visa stream, reported that just over a third came to New Zealand to be with family, partner or friends (Ministry of Business Innovation \& Employment, 2012). This migration stream is a mixed category that could include chain migration, trailing spouses, those 
with New Zealand partners, as well as family reunification. In effect, it is so broad that it reveals relatively little about what specific motivations are driving inward migration. However, it was also reported that $13 \%$ of migrants gave relaxed pace of life, and $11 \%$ listed environment/landscape as their main reason for coming to New Zealand. Ability to get a good job was also listed by $11 \%$ of the migrants. Thus, numerous factors have been identified as reasons to move, but having reasons is not the same as acting on those reasons.

There is a lack of clarity around how people shift from wanting to move internationally to actually doing so. After conducting a nationally representative 5-year longitudinal study of Dutch nationals with intentions to move internationally, van Dalen and Henkens (2012) observed that 'moving from intentions to behaviour is largely unexplained' (p. 11). Previous studies have highlighted that the pre-departure period can be long and tedious (JasinskajaLahti \& Yijälä, 2011; Tabor \& Milfont, 2011). Migration decision-making has been described as a series of decisions, rather than a once and done decision that characterises much of the literature on decision-making (De Jong, 1999; Sly \& Wrigley, 1986). Thus, our first research question is how do people make a decision to leave their country of origin?

\section{Destination Selection}

Destination selection usually falls within the realm of tourism studies (Baloglu \& McCleary, 1999; Crompton, 1992; Crompton \& Ankomah, 1993). It is also critically important, yet largely ignored, in international migration research (Roseman, 1983). Part of the migration choice is the elimination of what is potentially a long list of alternative countries. New Zealand sees itself as competing for skilled migrants (Hawthorne, 2011; Ho, 2001), but the extent to which a potential migrant considers multiple countries as destinations before selecting New Zealand is as yet unexplored. Certainly, skilled migrants have choices in destinations, as their educational and professional background gives them the access to legally work in a variety of countries.

Even so, there are external limitations that are a factor in destination selection, such as visa requirements, health requirements and financial resources. It is important to recognise that even though a destination is open to accepting migrants, they may be highly selective in whom they allow to enter. The United States is perhaps the most restrictive, but Canada, Australia and New Zealand all use selection criteria based on skills, education, and character (Hawthorne, 2011). It is for this reason that the present study focuses on skilled migration, rather than family reunification or refugee movement, because skilled migrants have the most choices in the migration decision-making process. However, even within this group, we recognise that choice does exist only within the boundaries created by policy and personal circumstance. Still, for those with options of destinations, how do they select a country to move to?

\section{Overview}

What can make a person move from just thinking about migrating to actually going? When many possible destinations offer similar benefits, how do migrants choose New Zealand to move to? Thus far, research has rarely ventured into the pre-departure period to explore the process of decision-making among international migrants, particularly using a qualitative methodology. Even more rare are studies that consider destination selection among skilled migrants who have the most choices about where to settle. In sum, the purpose of this research is to (a) explore how people make a decision to leave their country of origin, and (b) investigate how they select a destination. To accomplish this, we conducted a qualitative study using thematic analysis to identify similarities and differences between migrants to New Zealand.

\section{Methods \\ Sample}

Inclusion criteria followed two steps. Countries were first selected for inclusion based on number of visa approvals, with the top five source countries for skilled/business applications approved in 2009 ranked from highest to lowest: United Kingdom, South Africa, Philippines, China, India (Department of Labour, 2010). In addition, economic diversity was considered as it is an important consideration in economic theories of migration decision-making. The United Kingdom/Ireland was selected for high wages and South Africa for similar wages to New Zealand, and India as a low-wage sending country (Bureau of Labor Statistics, 2012a, 2012b; International Labour Organization, 2013). The United Kingdom and Ireland are combined in all Immigration New Zealand statistics, so these countries were considered as a single group in this study, though they are separate nations.

Following ethical approval granted by the School of Psychology Human Ethics Committee, interview participants were sought from online forums for migrants to New Zealand, blogs, and through snowball sampling. Snowball sampling was particularly successful for the South African sample, but the posting of a request for participants in online forums for migrants to New Zealand garnered more than the required number of participants from all countries. In total, 20 pre-departure (43.5\%) and 26 post-arrival migrants were included in the study. Fifteen participants were originally from South Africa, 15 from India, and 16 from the United Kingdom/Ireland. Of the pre-departure sample, the time to departure was extremely variable: people intended to move to New Zealand as early as one month from the date of the interview to years later. Of those already living in New Zealand, the mean time since arrival was 3.5 years $(S D=35$ months, 
range 6 months to 13 years). Seventy-five per cent had been in the country less than 5 years.

There were 26 women $(56.6 \%)$ and 20 men interviewed. The mean age of the total sample was 38.81 $(S D=8.3$, range 27 to 61$)$. Mean family size was 3.1 $(S D=1.6$, range 1 to 6$)$. Eighty per cent of the sample was in a committed relationship, and most couples were in heterosexual relationships. The majority $(82.6 \%)$ held a bachelor's degree or higher. Forty-four per cent had visited New Zealand prior to their move. Though it was more common for the UK/Irish and Indian sample, a total of $58.7 \%$ had lived outside of their country of origin previously. At the time of the interview, $76 \%$ intended to remain permanently in New Zealand. The skilled migrant category visa was the most common $(82.6 \%)$, though arrival with student, work, and business visas were also represented. Career fields included education, medicine, IT, sports, engineering, and hospitality. The Indian sample was overwhelmingly IT focused.

\section{Procedures}

All interviews were conducted between July and October 2011. Interviews were conducted using videoconferencing on Skype, or over the telephone, depending on the physical location and preference of the participants. All interviews were digitally audio-recorded and then transcribed. The mean interview time was 40 minutes ( $S D=20$ minutes, range 10 minutes to 1 hour 17 minutes), plus non-recorded debriefing. The study as a whole had 24 hours and 44 minutes of recorded data in the corpus. All names listed are pseudonyms, chosen from popular baby names in the respective country.

Interviews began with an introduction that included a brief explanation of the first author's own background as a migrant to New Zealand, to acknowledge that the researcher's experience, assumptions, values and cultural background are part of the reflexive experience of conducting qualitative research (Gearing, 2004; Shaw, 2010; Tufford \& Newman, 2012). The interview schedule had 10 questions, including 'Tell me the story of how you came to New Zealand' (post arrival) or 'Tell me how you started thinking about moving to New Zealand' (pre-departure). At the end of each interview, participants were debriefed and given the chance to ask questions. Participants were compensated for their time with a food (supermarket vouchers for those within New Zealand) or book voucher (Amazon.com for pre-departure participants). After the interviews were transcribed, participants were offered the chance to read and comment on their transcripts, and 17\% of participants did so. These comments were added to the corpus before analysis.

\section{Data Analysis}

Nvivo 9 was used for tracking each code and theme, as well as mapping the themes. Each country was analysed separately to allow the country's codes and themes to emerge independently of the overall themes of the data. Data were analysed according to steps outlined by Braun and Clarke (2006). Beyond the recommendations from Braun and Clarke, additional techniques were used both in the development and verification of the themes. Though the analysis of qualitative research is normally conducted behind closed doors, in what the community under study might view as a mystical process, Morse, Barrett, Mayan, Olson, and Spiers (2002) argue for including additional perspectives as a constructive (during the process) versus evaluative (post hoc) approach, as a means to increasing reliability and validity in qualitative research. Therefore, a second coder assisted with both the refinement of the initial themes in the South African part of the study, which was the first to be analysed, and to confirm themes in the India and UK/Irish parts of the study. Apart from this formal second coder, the initial themes were also discussed with the co-authors to clarify and arrive at the final themes. By increasing collaboration and auditing during the analysis, the coherence in the interpretation of the data is correspondingly increased (Smith, Flowers, \& Larkin, 2009).

Another technique we used in the development and verification of the themes was Miles and Huberman's (1994) tactic for testing or confirming findings: getting feedback from participants and other community members. This is similar to Tashakkori and Teddlie's (1998) member checks, whereby people from the community under study give feedback on conclusions. They perceive this as the single most important check of credibility that a researcher can utilise. Thus, a final report of findings was prepared, corresponding to the respective results sections for each country, and sent out to participants from the country as well as other community members who did not participate in the study, but who were gathered from personal networks or from contacts made during the interview process. All countries had more people offer to be interviewed than space allowed, and thus several of these people were contacted to give community feedback. All were invited to comment and to disagree. Overall, the comments confirmed the findings, and where they diverged, usually by adding more material or correcting an error such as spelling, have been incorporated into the findings.

In the initial round of open coding (highlighting any relevant portions of text and assigning them a code) and the second round of closed coding (identifying any text that fits within the identified codes), 110 codes were identified in the South African dataset, 70 for UK/Ireland, and 46 for India. Initially, a total of 1,868 extracts were coded. After refining the themes to check for internal homogeneity and external heterogeneity, the final dataset included 1,564 coded extracts in 43 themes and subthemes. As shown in Table 1, there was substantial overlap between themes and subthemes between the countries. Themes relating to settlement, degree to which expectations were met, and the decision to onward or return migrate were 
Table 1

Themes and Subthemes for South African, Indian and UK//rish Samples

\begin{tabular}{|c|c|c|c|}
\hline & $N$ (interviews) & $N$ (extracts) & $\%$ Country dataset \\
\hline \multicolumn{4}{|l|}{ South Africa } \\
\hline Quality of life & 13 & 69 & 10.1 \\
\hline Decision-making & 12 & 43 & 6.2 \\
\hline Catalyst & 11 & 22 & 3.2 \\
\hline Inhibitors/promoters & 12 & 38 & 5.5 \\
\hline Technology & 12 & 24 & 3.5 \\
\hline Intrapersonal factors & 13 & 61 & 8.9 \\
\hline Social Factors & 13 & 147 & 21.5 \\
\hline Settlement & 13 & 80 & 11.7 \\
\hline Country comparison & 1 & 1 & 1 \\
\hline Perceptions of South Africa & 13 & 55 & 8.1 \\
\hline Perceptions of New Zealand & 13 & 87 & 12.7 \\
\hline Other countries considered & 12 & 41 & 6 \\
\hline Cultural similarities & 8 & 15 & 2.1 \\
\hline \multicolumn{4}{|l|}{ United Kingdom/Ireland } \\
\hline Decision-making & 14 & 54 & 12.4 \\
\hline Couples decision-making & 10 & 33 & 7.6 \\
\hline Micro factors & 8 & 18 & 4.2 \\
\hline Adventure/Risk & 7 & 14 & 3.2 \\
\hline Work & 14 & 35 & 8 \\
\hline Social factors & 11 & 19 & 4.4 \\
\hline Extended Family & 12 & 16 & 3.7 \\
\hline Connections in New Zealand & 10 & 14 & 3.2 \\
\hline Children & 8 & 19 & 4.4 \\
\hline Macro factors & 0 & 0 & 0 \\
\hline Environment & 15 & 54 & 12.4 \\
\hline Lifestyle & 13 & 41 & 9.5 \\
\hline Friendliness & 14 & 22 & 5.1 \\
\hline Cultural similarity & 12 & 20 & 4.6 \\
\hline Crime/terrorism & 6 & 12 & 2.8 \\
\hline Cost of living & 6 & 7 & 1.6 \\
\hline Settlement & 15 & 55 & 12.7 \\
\hline \multicolumn{4}{|l|}{ India } \\
\hline Opportunity & 12 & 51 & 11 \\
\hline Work & 13 & 87 & 19 \\
\hline Lifestyle & 9 & 37 & 8 \\
\hline Social aspects of migration & 12 & 33 & 7 \\
\hline Extended family & 11 & 29 & 6 \\
\hline Partners decision-making & 8 & 21 & 5 \\
\hline Cultural norms & 10 & 21 & 5 \\
\hline Destinations & 11 & 49 & 11 \\
\hline Return or onward migration & 12 & 30 & 7 \\
\hline New Zealand & 11 & 21 & 5 \\
\hline Environment & 11 & 32 & 7 \\
\hline Destination in New Zealand & 9 & 11 & 2 \\
\hline Settlement & 10 & 26 & 6 \\
\hline
\end{tabular}

identified, but not reported in the present study due to relevance to the research questions.

\section{Results}

Based on the literature reviewed above, we expected to find that migrants would discuss their decision of whether to migrate and where to migrate. We did not expect the extent to which the timing of the decision, or when to migrate, would be of critical importance. In the following section, we will focus on the similarities between countries as they relate to this three-part process. This will address key players in the decision of whether to migrate (an individual, a couple, the extended family). In the question of selecting among destinations, we will concentrate on the themes and subthemes that were present within each country's data, including: quality of life, opportunity (career, financial and educational reasons), environment, safety, welcome, and social connections. Finally, to describe how the decision of when to go was managed by the participants, we will discuss the concept of a catalyst and the overall length of the decision process. Within each of these sections, differences between countries will also be highlighted.

\section{Whether to Migrate}

For nearly all of the migrants interviewed, the initial step in the decision process was to assess whether or not to leave their country of origin. This entailed a number of 
factors, the most central of which were intrapersonal, but social factors, such as the opinion of intimate partners and extended family members, were also key in the decision.

Intrapersonal factors. Several participants highlighted how risky the migration choice was, particularly for those who had not visited New Zealand or did not have a job waiting for them. Brandon compared himself to his brother, who remained in the United Kingdom: 'We are extremely different personality wise. I'm not sure he would even take that kind of risk, because it's quite a big leap that we are taking, to just go without a job and just go for it. But I'm not sure my brother would ever do that. We are very, very different in that respect.'

Kate, a South African, is a novelty-seeker: 'I see myself as an adventurer, I love the challenge, I like to try new things.' This is in contrast to her partner, Sam, who is somewhat risk-averse: 'I definitely see it as an unknown, and I'm not sure if things are going to work out. You know, I'm only making sure that things are going to be $100 \%$ and work out it's fine, but this is very risky as far as I'm concerned and you don't know what's going to happen when you get there, how things are going to pan out.'

Intimate partners. There were many gradations of desire to migrate that were expressed by the two partners. Some couples were in agreement on the move nearly from the start. Grace, a South African educator, and her partner 'were absolutely in it together'. But for many of the other couples from all the countries, there was a driver who had a stronger to desire to migrate than their trailing partner. These drivers convinced their partners, as Brandon's story illustrated:

We have been together for four years and we have been talking about it a lot and we do have long conversations about it and because it's obviously not just about making me happy, it's about her as well. So we have got to make sure that it's the right move for her also and if she ever said that she didn't want to go, she was adamant that she changed her mind that we would still consider that seriously and I would have to give up on the New Zealand dream, but I guess it works for both of us at the moment.

Trailing spouses, who are initially lower in the desire to move, often influenced the timing of the migration. Logan, a South African engineer, described the timing of his move: 'I think it was my idea in the beginning and quite a while back, about 10 years ago, I wanted to leave already and my partner didn't think so . . . she was totally against immigration at first, but it was her idea the second time round and of course mine as well.' These differences of migration desire complicate the process, engendering lengthy negotiations for most families, and emotional costs for both partners. Hannah moved to New Zealand because her partner wanted to, but the process of leaving the United Kingdom was extremely emotional for her: 'I wasn't really happy at all . . . I was really depressed. No, I found it really difficult.' Hannah was not unique in the painful experience of migrating to a country that she was not at all pleased to be moving to, and these negative feelings prior to the move made settling difficult. Not all families that differed in initial migration desire remained so polarised. Some trailing spouses were quickly convinced of the benefits of the move and became enthusiastic supporters of the plan.

Extended families. The issue of extended family members' roles in the migration decision was complex and varied by family as well as country. For some couples, like Kate and Sam, the extended families were divided: 'We've got my family supporting us and his saying no.' For Andries, extended family in South Africa were having an influence on the timing of the move: 'With my parents, they're getting pretty old now so ... that for me is probably the major thing holding me back.'

Indian families had the most central role for extended family members. For most of the Indian migrants, parents were a very important part of the decision-making process itself. Durva, who is unmarried, has been encouraged by her parents: 'They are really supportive and they are helping me find my way over.' Geeta described how her father encouraged her to support her husband's plans to move abroad, thereby convincing her to go.

I was a bit upset when he said we are going to immigrate and we are going to New Zealand.. . I said we are happy here, why do we want to move? So when I was talking to my parents, my father was the one who insisted I encourage my husband... what my father said was, 'Look if he wants to do something you do it now when your kids are young, when we are here to help you if you need any help... this is the best time to do it, to explore new ideas and if you think you are not settled if you don't like there you can always come back.'. . And because of the promising words I said to my husband, okay let's go.

Her narrative illustrated the collective nature of the migration decision for Indian migrants, with a much greater role for extended family members than was evident in British or South African families.

\section{Where to Migrate}

Nearly all participants considered where they would move to as the second major decision in the process. The strategies they employed were largely conjunctive, considering elements such as language, safety and job opportunities as a way to eliminate possible destinations.

Quality of life. The constructs of pace of life, quality of life, work/life balance and lifestyle were very much entwined. 'The city itself, the way everything worked, the quality of life there. I kept on saying that all the time there, the quality of life,' Reece, a self-employed South African, said of his trip to New Zealand. 'Peace of mind is a major thing for me, even more than money,' explained Lokajit. Jihan, an IT professional from Tamil Nadu, said that 'quality of life' was his top reason for leaving. Lifestyle was one of Rishi's main reasons: 'In India, even if you make a lot of money you cannot guarantee a certain lifestyle. So I thought of moving to a Western country, for a better lifestyle, for my kid.' 
In sum, there was a strong desire to 'downshift' and have a less hurried life. Several participants brought up work-life balance as a goal. Lokajit's friend moved to New Zealand before him, and told him about the difference in work-life balance: 'He would just tell us about the work culture, it's only working like 8 or 9 hours a day, and we used to work 10 or 12 hours a day in India.' Naadir, an IT professional from Kerala, was of the opinion that 'money, it doesn't really compensate for the lack of work/life balance'. Even in the United Kingdom, work and commuting consumes life. Ben expressed his frustration with lack of time for leisure activities: 'In the UK [it] is like you are up early, you go to work, come home and that's about it.'

Safety. 'Because the crime is not only theft, it is violence. Quite often it will be more than just your things that are taken,' warned Sam, a South African engineer and father. Every South African participant discussed safety as pivotal to the move. Though India has its own terrorism and crime threats, this did not come up in the interviews. Crime was an issue for UK participants, including Harry: 'It was right on our doorstep, the crime ... just the perception really, just seems to be getting worse.'

Opportunity. Indian participants stated that jobs, usually for both partners, were an important factor in both the ability to move abroad and in the appeal of moving abroad. Rishi, a young father from Tamil Nadu said that to develop a career, 'the IT professional in India has got to go abroad'. For several of the participants, part of the appeal of working overseas was to gain a higher salary. Durva clarified her reasons for the move: 'I could probably earn a lot more outside of India, just think of the exchange rate.' Others strongly denied salary or money was motivating their move. Rishi said: 'I'm having a good life in India. We have plenty of money here.' Dakshi, an engineer from Tamil Nadu, explained how his priorities had changed over time: 'When I moved initially [to the United States], yes, money was the main reason and then after gaining so many years of experience ... the money you can earn in the States or anywhere abroad, you can almost get the same amount of money these days in India.' It was clear that money was one factor among many that influenced the decision to move. For British and South African migrants, having the opportunity for a job was a factor that was considered in the decision, but career development was often a secondary factor.

Environment. Climate is one of the leading ways that migrants eliminated options from their potential list of destinations. For Georgia's family, like many of the others from the United Kingdom, 'the cold crossed off Canada'. 'Australia, no, just because it's too hot for us. We don't like the heat very much,' said Gwyn, another UK migrant. Indian migrants also were concerned with the climate. Farzana said, 'I heard about New Zealand, we heard about the climatic conditions, it was very good because, we both can't stay in a very hot climate.' In contrast to Australia's sweltering heat and Canada's snowy winters, New Zealand was perceived as having a Goldilocks climate, not too hot and not too cold.

Accessibility of nature and cleanliness were also important environmental attractions. On his first visit, Tyler, a South African, was awed by 'the place itself, the beauty of New Zealand, that was the first feeling, like amazing sight. Because you see photographs and stuff but you don't realise what it is or what it looks like before you get here. It was just amazing.' Andries also noted the natural environment: 'It's close to mountains, you're close to the sea, the outdoors, which for me is important.' Kumari's husband, who moved to New Zealand before her, described it for her: 'He told me that pollution is not a problem, very clean roads and not lots of traffic ... and a very beautiful place.'

Cultural similarity. When potential migrants consider destination countries, one of the first criteria they use is cultural similarity, starting with language. 'I was considering moving to English speaking countries because I didn't want to learn a new language for moving to a new country. So I was thinking of moving to either Canada, UK, Australia or New Zealand,' said Rishi. When migrants are attempting to eliminate destination options, language is a common and relatively straightforward method.

Not just culturally similar, New Zealand is reminiscent of an ideal Britain that does not exist anymore. 'It's kind of like England used to be when I was growing up,' said Ben. Harry described New Zealand as: '. . . almost like it used to be here 35,40 years ago in the UK. So it's got to be a better place.'

Sport was another important aspect of culture that helped attract the attention of the migrants. Rugby has proven that it is more than just a sport, it is a way to change lives, as illustrated by Tyler's comment: 'I suppose it started with the rugby of course. You've heard of the rugby. For me, either Australia or New Zealand, because their cultures are the same as South Africa. We love the same things, we do the same stuff and that's why I didn't consider any other country.' Cricket was also mentioned, particularly by Indian migrants.

Welcome. 'Initially I was looking for countries that were welcoming migrants,' explained Jihan. Naadir selected his destination the same way: 'New Zealand seemed more migrant-friendly.' The receptivity of the destination is expressed in both the availability of visas and the reception that migrants receive in the country. Half of the Indian participants specifically mentioned racism as having an impact on their decision-making. Australia's violence against Indian migrants ${ }^{1}$ has clearly made some people stay away. 'We thought of going to Australia but . . . because it was a time that kind of racist incidents were going on. Indians had gotten beaten up and all that stuff was going on in Australia,' Dakshi explained. The perception that New Zealand wants migrants was a crucial aspect of its selection as a destination. Availability of visas, the clarity of the Immigration New Zealand website and the expectation of a friendly host population were all part of the judgment. 
Social connections. Migrants' initial idea to come to New Zealand, rather than another country, very often came from a social connection to the country. Having friends in New Zealand influenced Kumari's husband:

He had his friends in New Zealand. That's why he wanted to come there, they are friends from his childhood. They told him that it's a very nice country, very beautiful place and so many tourists visit there and they play the same sports, so that's why he was really excited to go there.

Chain migration was a factor for many of the migrants, particularly those from South Africa and the United Kingdom who had extended family members already living in New Zealand, though for most, the connections were distant (i.e., great-uncle, second cousins). In the Indian sample, very few had family members living in New Zealand, but many had friends from their schooling. Reece, a pre-departure South African, said: 'We have very good friends there.. . .We grew up together; we used to race carts and do all kinds of crazy things. They immigrated 14 years ago. We've always stayed in touch.' Tegan, a South African businesswoman, has a pre-formed social network that creates a 'support structure because you've got all these people you know'.

\section{When to Migrate}

After the decision of where to settle was made, migrants usually focused on selecting the right time to go. This could be a drawn-out process, as the negotiation between family members was often lengthy.

The catalyst. 'I think the final straw was when we were burgled when my son and myself were alone in the house and they were in the house while we were sleeping. That was the final straw for me,' said Tegan. The catalyst theme relates to the events that crystallised the decision from an amorphous desire to leave into action to make that desire a reality. Not all catalysts related to violence or negative events. Carmen, a South African computer specialist, recently fell in love with a New Zealander:

New Zealand jumped to the top of my list, I may not have thought about New Zealand, I may have gone to Australia before I met him, but now after having learned about New Zealand and all that cool stuff you can do there. I'm thinking why didn't I think about it before?

Length of the decision process. Ultimately, the migration decision occurs within the context of time, which may span months or years. When asked at what point he started considering migration, Eka, an engineer from Maharashtra explained:

The roots go way back at the time when I was a child, when I used to think what it would be like, I used to wonder what it would be like to live in a different country. Although I had no background and no one to guide me in that, I still fancied those types of parts [more developed countries].

Some families related that they had been considering migration for more than 10 years, whereas one participant had made the decision a month prior to the interview and her ticket for departure was only 4 weeks away. Ben, a UK teacher, had desired an international move for years: 'It's been my mission since I went to Australia when I was 16 to move over that side of the world.' Timing can also be influenced by completely external factors such as health, jobs, schooling and visas, as Sam, who is still in South Africa, explained: 'So it was basically 2008 that we decided to try and which was when the global economic doom hit.'

\section{Discussion}

The purpose of this research was to explore how people make a decision to leave their country of origin and how they select New Zealand as a destination. For the South African, Indian and British migrants, the decision process was composed of three distinct parts. By and large, people first made the decision of whether, then where to migrate, and finally when to go. Nearly all participants had already exhibited long-term sustained effort to realise their migration plans; all perceived it as having a level of uncertainty and risk (though there were individual differences in comfort level with the risk), and all negotiated the decision with partners and/or close family members. The selection criterion for destinations was also remarkably similar. Clearly, there is a consistent message that New Zealand sells, as those who come here are essentially drawn to the same features (e.g., quality of life, environment, feeling welcome).

Thus, the process was first for there to be interest, from at least one partner, followed by investigations of possible destinations. Self-selected migration stems from intrapersonal factors, such as the desire for adventure and novelty. For some migrants, particularly in the case of South Africa, external events were conceptualised as a tipping point or last straw, as has been found previously (Du Toit, 2003; Visser, 2007). Yet these external events, or catalysts, do not cause a move. A catalyst is an external influence that the migrant perceives as spurring action, but the event in and of itself would not have the same impact if the person was not already considering a move. The catalyst interacts with an existing situation to move the person from a state of considering moving, into acting on their desire.

If a person reacts to a catalyst, inhibitors and promoters become important in the decision of whether or not to migrate to a certain destination. Triandis (1977) used the term facilitating factors to describe a similar concept. Some factors can make the move easier, such as a career that is highly portable or a job opportunity in the destination country. These factors alone do not make people migrate, but they grease the wheels to make the transition from simply wanting to go, to actually leaving, easier. Inhibiting factors include having a trailing spouse who does not want to move, health issues, having a less supportive extended family, and having fewer career options. If a person is not predisposed to migrate, facilitating influences 
(e.g., availability of visas, job opportunities) have little effect.

A negotiated decision. This research has supported previous findings on how families make migration decisions together (Adams, 2004), and expanded the understanding of the role of extended families in the decision. All of the countries had themes that included the issue of how differences in migration desire were negotiated between partners.

Among all nationalities, there were examples of trailing spouses agreeing to a move that was against their own wishes, purely to make their partner happy, or because they felt the children would be better off. This has also been noted in German migrants to New Zealand (Bürgelt, Morgan, \& Pernice, 2008). Drivers in this study discussed 'self-induced' pressure to make the move a success, which is similar to previous findings (Tabor \& Milfont, 2012). Rubin (2013) found that men were more likely to be the driving force in decisions to migrate to Australia. In this study, many of the women were more enthusiastic about the move than their partner, though, as with male trailing spouses, many began in a less receptive state to the move. Although trailing spouses have been discussed extensively in the academic literature (Adams, 2004; Bielby \& Bielby, 1992; Harvey, 1998; Tabor \& Milfont, 2012), this study found that the concept of a trailing spouse should be less categorical and more situational. This fluidity in migration desire is an important consideration for further research.

Social networks. Though some of the UK and South African migrants had social networks through kinship ties in New Zealand, it was clear that this was not the reason for the move. Unlike research with other migrant groups (Massey, 2004; Palloni et al., 2001), there was minimal expectation that social capital would increase the chances of finding jobs or housing. It may be that skilled migrants have less need of these support systems than do unskilled migrants who arrive at their destination with very limited financial resources.

The situation of some extended family members being supportive while others were firmly against the move was also very common. The main exception to this was India, where some participants said that their extended family members were as important to the decision as the couple (or individual) themselves. Research with Irish migrants has also shown that extended family can have a strong role, particularly in destination selection even in individualistic cultures (Ryan, 2008, 2009). In the Indian sample, not all extended family were supportive, particularly of New Zealand as a destination, instead encouraging migrants to go to places with more social networks to support them (such as Canada, Australia or the United States).

Migration as opportunity. Work was a subtheme for both UK and Indian migrants; however, it was much more prevalent in the India dataset (19\% vs. $8 \%)$. In South Africa, it was one of many intrapersonal factors that facilitated migration, rather than a reason for the move. Only one person in the study was migrating to New Zealand purely because they had a job offer; all others were seeking to move to New Zealand and therefore looked for a job before or after arrival. This concept of work as a way to facilitate a desired move was also found in internal migration studies in the United Kingdom (Boyle, Halfacree, \& Robinson, 1998).

If a single idea can encapsulate what all of these migrants are seeking, it is an improvement in quality of life. Quality of life, in the form of lifestyle, pace of life and work-life balance was a prominent theme for all three countries. Inglehart (1997) found that in a society that had reached a high level of material wealth, people tend to start focusing more on immaterial aspects, such as quality of life. In previous research, lifestyle migration had a quality similar to retirement migration, a seeking of leisure pursued by those who could afford not to work (Benson \& O'Reilly, 2009). Yet the migrants in the present study, who very often did give lifestyle as a reason for their move, were clearly planning to work upon arrival. One Indian participant referred to seeking 'a more balanced life' and this is a very good description of what these lifestyle migrants were searching for. A satisfying career, but balanced with time for leisure and access to nature, were the key qualities that the migrants pursued.

\section{Same, Same But Different: How Migrants Select a Destination}

Migrants did not consider an exhaustive list of every possible destination country. Most started from a short list of possibilities, and this list was influenced by family, friends and media. Attractive aspects that led to the selection of New Zealand as the destination included welcome, cultural similarity and environment.

Migrants wanted. New Zealand was viewed as hospitable to migrants, which has been supported by previous research (Ward \& Masgoret, 2008; Ward, Masgoret, \& Vauclair, 2011). It was also seen as accessible, in that the migration policies were open enough to allow legal entry. The higher threshold for visas that Australia imposes, and the complicated system varying by state were seen as indications that Australia has less desire for migrants. The United States and the United Kingdom also had much more strict policies of entry, and it is this openness that helped create a path of least resistance to New Zealand.

Cultural similarity. Aspects of culture have previously been demonstrated as part of the internal migration process, as Mormons reported that their move to the U.S. state of Utah was driven by religious as well as family motives (Kontuly et al., 1995). The present study went further, finding that the cultural characteristics of a nation were key factors in destination selection. Despite many of the migrants speaking other languages, English language was the first criterion used by most migrants as a conjunctive strategy, thereby ruling out all potential destinations where English is not the language of business. More 
general cultural similarities, such as sports, were also important selection criteria for migrants.

Environment. From the perspective of destination selection, environment is one of the best-selling features of New Zealand. Though these migrants came from a range of climate zones, all viewed the relatively mild New Zealand climate positively. Migrants had considered but ruled out Canada because it is too cold and Australia because it is too hot. Even Indian migrants sometimes saw Australia as too warm, though they were also concerned that they might be too cold in New Zealand, and thus favoured migration to the northern part of North Island where the weather is more tropical. The sentiment that Canada is too cold and Australia is too hot but New Zealand is just right echoes the 'Goldilocks Effect' that planetary scientists use to describe ideal climates.

Beyond temperature, New Zealand's scenery and access to nature were attractions for all nationalities. Positive evaluations of the environment were very much in line with research on place attractiveness in the migration decision (Ewers, 2007; Li, Holm, \& Lindgren, 2009; Niedomysl, 2010). The mild climate, beautiful scenery, accessibility of nature and pollution-free reputation of the country were key draws.

\section{Time in the Migration Decision}

In the South African dataset there was a clear and immediate catalyst for the move from almost all the participants, whereas for the other countries the process seemed to be a gradual realisation that the time for the move was right, usually because of life stage. For all of the countries, most people seemed to be 'primed' to move, just waiting for the opportunity to open for them to actually leave. The timing of the migration itself is not widely discussed in the research literature; it has been called the forgotten dimension (Shotter, 1984), though some studies have addressed how migration fits in the lifespan such as the case of retirement migration (Bolzman, Fibbi, \& Vial, 2006). What was clear in the present study was that when to move was an important and distinct decision, and one that was often influenced by external factors. Even for those who had a willing partner, migrants spoke about the frustration of changing visa regulations in potential destinations. The global economic downturn had a strong impact on international migration flows (Green \& Winters, 2010; 'The people crunch: Global migration and the downturn', 2009), making some potential migrants act more conservatively (Parsons, Tabor, \& Fischer, 2012). Being willing to go is not the same as being able to go.

\section{Limitations and Conclusions}

Subjectivity is a common critique of qualitative research, and in this case every effort was made to check the findings. Participant and community feedback on the results was tremendously supportive. The aim was descriptive, which may be seen as a fundamental limitation. The sample size of each country's part of the study was large by qualitative research standards (Smith, Flowers, \& Larkin, 2009) but not large enough to draw inferential conclusions, being a small, non-random sample.

Within the New Zealand context, there was a limited selection of English-speaking sending countries (United Kingdom, India and South Africa) included in the sample, when the diversity of migrants is vast. This selection has likely meant that cultural similarity was an important destination selection criterion, when for many other sending countries this may not be a factor. Future studies with participants from non-English speaking countries are recommended.

Psychology tends to be bound by an individualist tendency: it puts priority on individual decisions while failing to appreciate that important real world decisions are essentially collective when the decision-makers are in a committed relationship, or part of a family that relies on parents, grandparents, children and even siblings in the decision-making process. The present study included numerous stories of how the couples had to reach a decision together, and particularly for Indian families, how important the role of the extended family was in the decision. Practitioners working with migrant families may benefit from this deeper understanding of what drives migration and the lengthy negotiation process that it entails for many partners. Additionally, policy-makers should be aware of both the decision-making process and how marketing, even that aimed at tourists, influences it. Finally, theories must address how the decision to migrate is not only comprised of three main choices (whether, where and when) but also how these are each situated within a cultural and social context.

This study elucidated the decision-making process of self-selected migrants, raising awareness of how this process can be influenced. Essentially there is a pool of wellqualified migration candidates who are at this moment looking for a destination. Thus, there is no need to convince people to migrate; there is only a need for countries to highlight how they can satisfy the needs of the migrants, and to assure them that they are indeed wanted.

\section{Endnote}

1 During 2009-2010 there were more than 100 reported incidents of attacks against Indians in Australia (The Indian Express, 2010).

\section{References}

Adams, J. (2004). 'This is not where I belong!' The emotional, ongoing, and collective aspects of couples' decision making about where to live. Journal of Comparative Family Studies, 35, 459-485.

Adelman, M.B. (1988). Cross-cultural adjustment: A theoretical perspective on social support. International Journal of Intercultural Relations, 12, 183-204. doi:10.1016/01471767(88)90015-6 
Amit, K., \& Riss, I. (2007). The role of social networks in the immigration decision-making process: The case of North American immigration to Israel. Immigrants and Minorities, 25, 290-313. doi:10.1080/02619280802407517

Anas, M.U.M., \& Wickremasinghe, S.I. (2010). Brain drain of the scientific community of developing countries: The case of Sri Lanka. Science and Public Policy, 37, 381-388.

Baloglu, S., \& McCleary, K.W. (1999). A model of destination image formation. Annals of Tourism Research, 26, 868-897.

Benson, M.C., \& O'Reilly, K. (2009). Migration and the search for a better way of life: A critical exploration of lifestyle migration. The Sociological Review, 57, 608-625. doi:10.1111/j.1467-954X.2009.01864.x

Bhattacharyya, B. (1985). The role of family decision in internal migration: The case of India. Journal of Development Economics, 18, 51-66. doi:10.1016/0304-3878(85)90006-9

Bielby, W.T., \& Bielby, D.D. (1992). I will follow him: Family ties, gender-role beliefs, and reluctance to relocate for a better job. American Journal of Sociology, 97, 1241-1267.

Bolzman, C., Fibbi, R., \& Vial, M. (2006). What to do after retirement? Elderly migrants and the question of return. Journal of Ethnic and Migration Studies, 32, 1359-1375.

Boneva, B.S., \& Frieze, I.H. (2001). Toward a concept of a migrant personality. Journal of Social Issues, 57, 477-491. doi:10.1111/0022-4537.00224

Boneva, B.S., Frieze, I.H., Ferligoj, A., Jarosova, E., Pauknerova, D., \& Orgocka, A. (1998). Achievement, power, and affiliation motives as clues to (E)migration desires. European Psychologist, 3, 247-254. doi: 10.1027/1016-9040.3.4.247

Boneva, B.S., Frieze, I.H., Ferligoj, A., Pauknerova, D., \& Orgocka, A. (1997). East-West European migration and the role of motivation in emigration desires. Migracijske teme, 13, 335-361. doi:10.1027/1016-9040.3.4.247

Boyd, M. (1989). Family and personal networks in international migration: recent developments and new agendas. International Migration Review, 23, 638-670.

Boyle, P. (2009). Migration. In K. Rob \& T. Nigel (Eds.), International encyclopedia of human geography (pp. 96-107). Oxford: Elsevier.

Boyle, P., Halfacree, K., \& Robinson, V. (1998). Exploring contempory migration. Harlow, Essex: Pearson Education.

Braun, V., \& Clarke, V. (2006). Using thematic analysis in psychology. Qualitative Research in Psychology, 3, 77-101. doi:10.1191/1478088706qp063oa

Bureau of Labor Statistics. (2012a). International labor comparisons: Country at a glance: India. Retrieved 17 May, 2013 from http://www.bls.gov/fls/india.htm

Bureau of Labor Statistics. (2012b). International Labor Comparisons: Country at a glance: United Kingdom. Retrieved May 17, 2013 from http://www.bls.gov/ fls/country/united_kingdom.htm

Bürgelt, P.T., Morgan, M., \& Pernice, R. (2008). Staying or returning: Pre-migration influences. Journal of Community \& Applied Social Psychology, 18, 282-298. doi:10.1002/casp.924
Bushin, N. (2009). Researching family migration decisionmaking: A children-in-families approach. Population, Space and Place, 15, 429-443. doi: 10.1002/psp.522

Carr, S.C., Inkson, K., \& Thorn, K. (2005). From global careers to talent flow: Reinterpreting 'brain drain'. Journal of World Business, 40, 386-398. doi:10.1016/j.jwb.2005.08.006

Castles, S., \& Miller, M. (2003). The age of migration: International population movements in the modern world (3rd ed.). Basingstoke, UK: MacMillan.

Chant, S., \& Radcliffe, S. (1992). Migration and development: The importance of gender. In S. Chant (Ed.), Gender and migration in developing countries (pp. 1-29). London: Belhaven Press.

Choldin, H.M. (1973). Kinship networks in the migration process. International Migration Review, 7, 163-175.

Connell, J. (2008). Niue: Embracing a culture of migration. Journal of Ethnic and Migration Studies, 34, 1021-1040.

Crompton, J. (1992). Structure of vacation destination choice sets. Annals of Tourism Research, 19, 420-434.

Crompton, J., \& Ankomah, P.K. (1993). Choice set propositions in destination decisions. Annals of Tourism Research, 20, 461-476.

Dashefsky, A., DeAmicis, J., Laserwitz, B., \& Tabory, E. (1992). Americans abroad: A comparative study of emigrants from the United States. New York: Plenum Press.

de Haas, H. (2010). The internal dynamics of migration processes: A theoretical inquiry. Journal of Ethnic and Migration Studies, 36, 1587-1617.

de Haas, H., \& Fokkema, T. (2010). Intra-household conflicts in migration decisionmaking: Return and pendulum migration in Morocco. Population and Development Review, 36, 541-561.

De Jong, G.F. (1999). Choice processes in migration behavior. In K. Pandit \& S. Davies Withers (Eds.), Migration and restructuring in the United States: A geographic perspective. Lanham, Maryland: Rowman \& Littlefield.

De Jong, G.F., \& Gardner, R.W. (Eds.). (1981). Migration decision making: Multidisciplinary approaches to microlevel studies in developed and developing countries. New York: Pergamon Press.

De Jong, G.F., Root, B.D., Gardner, R.W., Fawcett, J.T., \& Abad, R.G. (1986). Migration intentions and behavior: Decision making in a rural Philippine province. Population and Environment, 8, 41-62. doi:10.1007/BF01263016

De Jong, G.F., Warland, R.H., \& Root, B.D. (1998). Family interaction and migration decision making. Research in rural sociology and development, 7, 155-167.

Department of Labour. (2009). New faces, new futures: New Zealand. Findings from the Longitudinal Immigration Survey: New Zealand (LisNZ) - Wave one. Wellington, New Zealand: Author.

Du Toit, B.M. (2003). Boers, Afrikaners, and diasporas. Paper presented at the Seminar by the History Commission of the South African Academy of Science and Art, Pretoria, South Africa. 
Ewers, M.C. (2007). Migrants, markets and multinationals: Competition among world cities for the highly skilled. GeoJournal, 68, 119-130. doi: 10.1007/s10708-007-9077-9

Fawcett, J.T. (1989). Networks, linkages, and migration systems. International Migration Review, 23, 671-680.

Frieze, I.H., Boneva, B.S., Sarlija, N., Horvat, J., Ferligoj, A., Kogovsek, T., ... Jarosova, E. (2004). Psychological differences in stayers and leavers: Emigration desires in Central and Eastern European university students. European Psychologist, 9, 15-23. doi:10.1027/1016-9040.9.1.15

Frieze, I.H., Hansen, S.B., \& Boneva, B.S. (2006). The migrant personality and college students' plans for geographic mobility. Journal of Environmental Psychology, 26, 170-177. doi:10.1016/j.jenvp.2006.05.001

Frieze, I.H., \& Li, M. (2010). Mobility and Personality. In S.C. Carr (Ed.), The Psychology of Global Mobility (pp. 87103). New York: Springer

Gearing, R.E. (2004). Bracketing in research: A typology. Qualitative Health Research, 14, 1429-1452.

Georgas, J., Mylonas, K., Bafiti, T., Poortinga, Y.H., Christakopoulou, S., Kagitcibasi, C., . . . Kodic, Y. (2001). Functional relationships in the nuclear and extended family: A 16-culture study. International Journal of Psychology, 36, 289-300. doi:10.1080/0020759014300004 5

Gibson, J., \& McKenzie, D. (2011). The microeconomic determinants of emigration and return migration of the best and brightest: Evidence from the Pacific. Journal of Development Economics, 95, 18-29. doi: 10.1016/j.jdeveco.2009.11.002

Graves, P.E., \& Linneman, P.D. (1979). Household migration: Theoretical and empirical results. Journal of Urban Economics, 6(3). doi:10.1016/0094-1190(79)90038-X

Green, T., \& Winters, L.A. (2010). Economic crises and migration: Learning from the past and the present. World Economy, 33, 1053-1072. doi:10.1111/j.1467-9701.2010.01313.x

Gubhaju, B., \& De Jong, G.F. (2009). Individual versus household migration decision rules: Gender and marital status differences in intentions to migrate in South Africa. International Migration, 47, 31-61.

Hamer, M.C. (2008). Migration patterns and influence of support networks: A case study of West Africans in the Netherlands. Gender, Technology and Development, 12, 347-364. doi:10.1177/097185240901200304

Harvey, M. (1998). Dual-career couples during international relocation: The trailing spouse. The International Journal of Human Resource Management, 9, 309-331. doi:10.1080/095851998341116

Haug, S. (2008). Migration networks and migration decisionmaking. Ethnic and Migration Studies, 34, 585-605. doi:10.1080/13691830801961605

Hawthorne, L. (2011). Competing for skills: Migration policies and trends in New Zealand and Australia. Wellington, New Zealand: Department of Labour.

Ho, E. (2001). The challenge of recruiting and retaining international talent. New Zealand Journal of Geography, 112, 18-22. doi:10.1111/j.0028-8292.2001.tb00787.x
Ho, E., \& Bedford, R. (2008). Asian transnational families in New Zealand: Dynamics and challenges. International Migration, 46, 41-62. doi:10.1111/j.1468-2435.2008.00471.x

Hoang, L.A. (2011). Gender identity and agency in migration decision-making: Evidence from Vietnam. Journal of Ethnic and Migration Studies, 37, 1441-1457. doi:10.1080/1369183X.2011.623618

Inglehart, R. (1997). Modernization and postmoderniza tion: Cultural, economic, and political change in 43 societies. Princeton, NJ: Princeton University Press.

International Labour Organization. (2013). Global wage report 2012/13: Wages and equitable growth. Geneva: International Labout Organization.

Jasinskaja-Lahti, I., \& Yijälä, A. (2011). The model of pre-acculturative stress - A pre-migration study of potential migrants from Russia to Finland. International Journal of Intercultural Relations, 35, 499-510. doi:10.1016/j.ijintrel.2010.11.003

King, R., \& Skeldon, R. (2010). 'Mind the gap!' Integrating approaches to internal and international migration. Journal of Ethnic and Migration Studies, 36, 1619-1646.

Konseiga, A. (2007). Household migration decisions as survival strategy: The case of Burkina Faso. Journal of African Economies, 16, 198-233.

Kontuly, T., Smith, K.R., \& Heaton, T.B. (1995). Culture as a determinant of reasons for migration. The Social Science Journal, 32, 179-193. doi:10.1016/0362-3319(95)90004-7

Le, J.K., Tissington, P.A., \& Budhwar, P. (2010). To move or not to move-A question of family? International Journal of Human Resource Management, 21, 17-45.

Li, W., Holm, E., \& Lindgren, U. (2009). Attractive vicinities. Population, Space and Place, 15, 1-18.

MacDonald, J.S., \& MacDonald, L.D. (1964). Chain migration ethnic neighborhood formation and social networks. The Milbank Memorial Fund Quarterly, 42, 82-97.

Massey, D.S. (1999). Why does immigration occur? A theoretical synthesis. In C. Hirschman, P. Kasinitz, \& J. DeWind (Eds.), The handbook of international migration: The American experience (pp. 34-52). New York: Sage.

Massey, D.S. (2004). Social and economic aspects of immigration. Annals of the New York Academy of Sciences, 1038, 206212.

Massey, D.S., Alarcon, R., Durand, J., \& Gonsalez, H. (1987). Return to Aztlan: The social process of international migration from western Mexico. Berkeley and Los Angeles, CA: University of California Press.

Miles, M., \& Huberman, A. (1994). Qualitative data analysis. Thousand Oaks, CA: Sage.

Mincer, J. (1978). Family migration decisions. Journal of Political Economy, 86, 749-773.

Ministry of Business Innovation \& Employment. (2012). Immigration Survey Monitoring Programme-Migrants Survey 
Indicators: Migrants' reasons for coming to New Zealand. Wellington, New Zealand: Author.

Morse, J. M., Barrett, M., Mayan, M., Olson, K., \& Spiers, J. (2002). Verification strategies for establishing reliability and validity in qualitative research. International Journal of Qualitative Methods, 1(2).

Mulder, C.H. (2007). The family context and residential choice: A challenge for new research. Population, Space and Place, 13, 265-278. doi:10.1002/psp.456

Niedomysl, T. (2010). Towards a conceptual framework of place attractiveness: A migration perspective. Geografiska Annaler, Series B: Human Geography, 92, 97-109. doi:10.1111/j.14680467.2010.00335.x

Palloni, A., Massey, D., Ceballos, M., Espinosa, K., \& Spittel, M. (2001). Social capital and international migration: A test using information on family networks. The American Journal of Sociology, 106, 1262-1298. doi:10.1086/320817

Parsons, J., Tabor, A.S., \& Fischer, R. (2012). Shelter from the global economic crisis: New Zealand and overseas-born employees concerns and migration intentions Journal of Pacific Rim Psychology, 6, 48-56. doi:10.1017/prp.2012.8

Pedersen, P.J., Pytlikova, M., \& Smith, N. (2008). Selection and network effects - Migration flows into OECD countries 1990-2000. European Economic Review, 52, 1160-1186. doi:http://dx.doi.org/10.1016/j.euroecorev.2007.12.002

Pedraza, S. (1991). Women and migration: The social consequences of gender. Annual Review of Sociology, 17, 303-325. doi:10.1146/annurev.so.17.080191.001511

The people crunch: Global migration and the downturn. (2009). The Economist.

Rabe, B. (2011). Dual-earner migration. Earnings gains, employment and self-selection. Journal of Population Economics, 24, 477-497. doi:10.1007/s00148-009-0292-1

Roseman, C.C. (1983). A framework for the study of migration destination selection. Population and Environment, 6, 151165. doi:10.1007/BF01258957

Rubin, M. (2013). 'It wasn't my idea to come here!': Ownership of the idea to immigrate as a function of gender, age, and culture. International Journal of Intercultural Relations, 37, 497-501.

Ryan, L. (2008). 'I had a sister in England': Family-led migration, social networks and Irish nurses. Journal of Ethnic and Migration Studies, 34, 453-470. doi:10.1080/13691830701880293

Ryan, L. (2009). How women use family networks to facilitate migration: A comparative study of Irish and Polish women in Britain. History of the Family, 14, 217-231. doi:10.1016/j.hisfam.2009.02.004

Schoorl, J.J., Heering, L., Esveldt, I., Groenewold, G., van der Erf, R.F., Bosch, A.M., . . . de Bruijn, B. J. (2000). Push and pull factors of international migration: A comparative report (Vol. Theme 1 General Statistics). Luxembourg: Eurostat.

Shaw, R. (2010). Embedding reflexivity within experiential qualitative psychology. Qualitative Research in Psychology, 7, 233243.
Shotter, J. (1984). Social accountability and selfhood. Oxford: Blackwell.

Sly, D.F., \& Wrigley, J.M. (1986). Migration decision making and migration behavior in rural Kenya. Population and Environment, 8, 78-97.

Smith, J.A., Flowers, P., \& Larkin, M. (2009). Interpretative phenomenological snalysis: Theory, methods and research. Thousand Oaks, CA: Sage.

Stark, O., \& Taylor, J. E. (1989). Relative deprivation and international migration. Demography, 26, 1-14.

Statistics New Zealand. (2015). International travel and migration: February 2015 - Tables. Retrieved from http://www. stats.govt.nz/ $/$ media/Statistics/Browse $\% 20$ for\%20stats/ IntTravelAndMigration/HOTPFeb15/itm-feb15-tables.xls

Stecklov, G., Carletto, C., Azzarri, C., \& Davis, B. (2010). Gender and migration from Albania. Demography, 47, 935-961. doi:10.1007/BF03213734

Stone, I., \& Stubbs, C. (2007). Enterprising expatriates: Lifestyle migration and entrepreneurship in rural southern Europe. Entrepreneurship and Regional Development, 19, 433-450. doi:10.1080/08985620701552389

Tabor, A.S., \& Milfont, T.L. (2011). Migration change model: Exploring the process of migration on a psychological level. International Journal of Intercultural Relations, 35, 818-832. doi:10.1016/j.ijintrel.2010.11.013

Tabor, A.S., \& Milfont, T.L. (2012). Family social support during the predeparture period: The experience of British migrants. International Journal of Psychology, 1-9. doi:10.1080/00207594.2011.634008

Tabor, A.S., \& Milfont, T.L. (2013). We are all the in the same boat: How online communities facilitate the process of migration. New Zealand Journal of Psychology, 42, 31-35.

Tartakovsky, E. (2012). Factors affecting immigrants' acculturation intentions: A theoretical model and its assessment among adolescent immigrants from Russia and Ukraine in Israel. International Journal of Intercultural Relations, 36, 8399.

Tashakkori, A., \& Teddlie, C. (1998). Mixed methodology: Combining qualitative and quantitative approaches (vol. 46). Thousand Oaks, CA: Sage.

Thai, H.C. (2012). The dual roles of transnational daughters and transnational wives: Monetary intentions, expectations and dilemmas. Global Networks, 12, 216-232. doi:10.1111/j.1471-0374.2012.00348.x

The Indian Express. (2010). Four more Indians attacked in Australia. Retrieved April 10, 2012 from http://www. indianexpress.com/news/four-more-indians-attacked-inaustralia/572514/0

Triandis, H.C. (1977). Interpersonal behavior. Monterey, CA: Brooks/Cole.

Tsegai, D. (2007). Migration as a household decision: What are the roles of income differences? Insights from the Volta basin of Ghana. European Journal of Development Research, 19, 305-326. 
Tufford, L., \& Newman, P. (2012). Bracketing in qualitative research. Qualitative Social Work, 11, 80-96. doi: $10.1177 / 1473325010368316$

United Nations. (2013). 232 million international migrants living abroad worldwide - New UN global migration statistics reveal [Press release]. Retrieved from http://www.un.org/ en/ga/68/meetings/migration/pdf/UN press release_International Migration Figures.pdf

van Dalen, H.P., \& Henkens, K. (2007). Longing for the good life: Understanding emigration from a high-income country. Population and Development Review, 33, 37-66. doi:10.1111/j.1728-4457.2007.00158.x

van Dalen, H.P., \& Henkens, K. (2012). Explaining emigration intentions and behaviour in the Netherlands, 2005-10. Population Studies, 1-17. doi:10.1080/00324728.2012.725135
Visser, W. (2007). Afrikaner responses to post-apartheid South Africa: Diaspora and the re-negotiation of a cultural identity. New Contree, 54, 1-24.

Ward, C., \& Masgoret, A.-M. (2008). Attitudes toward immigrants, immigration, and multiculturalism in New Zealand: A social psychological analysis. International migration Review, 42, 227-249. doi:10.1111/j.1747-7379.2007.00119.x

Ward, C., Masgoret, A.-M., \& Vauclair, M. (2011). Attitudes towards immigrants and immigrant experiences: Predictive models based on regional characteristics. Wellington, New Zealand: Department of Labour.

Yijälä, A., \& Jasinskaja-Lahti, I. (2010). Pre-migration acculturation attitudes among potential ethnic migrants from Russia to Finland. International Journal of Intercultural Relations, 34, 326-339. doi:10.1016/j.ijintrel.2009.09.002 